\title{
BMJ Global Health Effects of a home-based participatory play intervention on infant and young child nutrition: a randomised evaluation among low-income households in El Alto, Bolivia
}

Sebastian Martinez, ${ }^{1}$ Julia Johannsen, ${ }^{1}$ Gaston Gertner, ${ }^{1}$ Jorge Franco, ${ }^{1}$ Ana B Perez Exposito, ${ }^{1}$ Rosario M Bartolini, ${ }^{2}$ Irma Condori, ${ }^{3}$ Jhovanna Flores Ayllón, ${ }^{3}$ Ramiro Llanque, ${ }^{3}$ Nohora Alvarado, ${ }^{1}$ Christian Lunstedt, ${ }^{1}$ Cecilia Ferrufino, ${ }^{1}$ Teresa Reinaga, ${ }^{1}$ Mauricio Chumacero, ${ }^{4}$ Carlos Foronda, ${ }^{4}$ Santiago Albarracin, ${ }^{4}$ Ana Maria Aguilar ${ }^{5}$

To cite: Martinez S, Johannsen J, Gertner G, et al. Effects of a homebased participatory play intervention on infant and young child nutrition: a randomised evaluation among low-income households in $\mathrm{El}$ Alto, Bolivia. BMJ Glob Health 2018;3:e000687. doi:10.1136/ bmjgh-2017-000687

Handling editor Seye Abimbola

Received 18 December 2017 Revised 14 April 2018 Accepted 16 April 2018

(D) Check for updates

${ }^{1}$ Inter-American Development Bank (IDB), Washington, DC, USA ${ }^{2}$ Instituto de Investigación Nutricional, La Molina, Peru ${ }^{3}$ Consejo de Salud Rural Andino (CSRA), La Paz, Plurinational State of Bolivia

${ }^{4}$ Universidad Privada Boliviana (UPB), Center for Generation of Information and Statistics (CEGIE), La Paz, Plurinational State of Bolivia

${ }^{5}$ Universidad Mayor de San Andres (UMSA), La Paz, Plurinational State of Bolivia

Correspondence to Dr Sebastian Martinez; smartinez@iadb.org

\section{ABSTRACT}

Background Stunting affects child survival and is a key indicator of child well-being. Therefore, reducing stunting is a global goal. Improving infant and young child feeding (IYCF) practices is a recommended approach to reduce the risk of mortality and ameliorate nutritional status. Behavioural change interventions have the potential to improve IYCF practices.

Methods We evaluated the effectiveness of an innovative behavioural change strategy on caregiver's knowledge, IYCF practices and nutritional status of children from lowincome households in El Alto, Bolivia. Home visits used culturally adapted participatory play strategies to promote recommended IYCF practices. A total of 2014 households with children younger than 12 months at baseline were randomly assigned to treatment and control groups.

Findings Caregiver knowledge and IYCF practices improved by $0.2 \mathrm{SD}$, as did food expenditures on recommended foods and dietary diversity. No significant effects were detected on anthropometric indicators or anaemia. Treatment compliance was $88 \%$ of households at enrolment and $66 \%$ at completion. Interpretation Participatory play-based behavioural change strategies are a promising delivery model to improve recommended IYCF practices. After 30 months of intervention, we found sustained positive effects on caregiver's knowledge and IYCF practices but no effect on nutritional status. Despite the lack of effect on linear growth and anaemia, our results highlight the relevance of implementing interventions that improve IYCF practices due to their importance for early development and prevention of obesity. Other contextual variables, apart from diet, that could be limiting children's growth potential in this population need to be identified to design holistic approaches that improve child well-being and human capital.

\section{INTRODUCTION}

It is well documented that stunting early in life affects adult height and cephalopelvic

\section{Key questions}

What is already known?

- Improvement of infant and young child feeding (IYCF) is needed to address all forms of malnutrition including stunting, obesity and anaemia.

- Behavioural change strategies that enable and encourage caregivers have the potential to improve IYCF practices, yet evidence of their impact on growth is mixed and effects on overweight, obesity and anaemia are rarely reported.

What are the new findings?

- A participatory play-based behavioural change strategy significantly improved caregivers' IYCF knowledge and practices.

- The impact on IYCF did not result in detectable effects on height, weight or anaemia nor did it produce unintended effects on overweight and obesity.

\section{What do the new findings imply?}

- The home-based participatory play intervention studied here is a promising way of providing IYCF education and counselling to generate knowledge acquisition and behavioural change and, coupled with other interventions, may be considered as part of an integral approach to improve maternal and child nutrition.

proportions, leading to poor maternal and neonatal outcomes. ${ }^{1}$ Stunting is responsible for the intergenerational effects of malnutrition due to its effects on intrauterine growth and birth weight. ${ }^{2}$ Stunting has also been shown to be a risk factor for child survival and a strong indicator of cumulative deprived environmental conditions that impede the achievement of a child's genetic potential 
for linear growth in several ways. ${ }^{3}$ Stunting early in life affects well-being and economic development due to its association with impaired development, school achievement, long-term health and productivity in adulthood. ${ }^{1-6}$ Therefore, reducing stunting has been set as a global development goal. Despite favourable trends in low-income and middle-income countries, pockets of high stunting prevalence persist. Moreover, these populations are increasingly accompanied by a rising prevalence of overweight and obesity, resulting in a double burden of malnutrition. ${ }^{78}$

The implementation of strategies to improve infant and young child feeding (IYCF) practices has been recommended globally to tackle all forms of malnutrition, including stunting and obesity. ${ }^{9-11}$ Evidence shows that behavioural change interventions that enable and encourage caregivers have the potential to improve IYCF practices. ${ }^{12}$ Successful behavioural change strategies should be based on a rigorous situational analysis and formative research to identify barriers and enablers and then used to design the strategy. They also require social mobilisation and existing support systems. Few programmes have implemented these recommendations with success. ${ }^{13}$ Moreover, evidence on the impact of behavioural change interventions on anthropometric measurements is mixed, from no changes to improvements in growth indicators, depending on the intervention design and context. ${ }^{14-20}$ In particular, impacts of education interventions on height-related growth are reported by very few studies, primarily in Asian countries and with only one study from Latin America, which does not provide community-based but rather professional nutrition education at health centres in Peru. ${ }^{21}$ Effects on overweight, obesity or anaemia are rarely reported.

Governments in the Latin American region, where stunting, anaemia, overweight and obesity are public health problems, are making important investments to implement strategies that improve IYCF practices. Evidence of nutrition education interventions that effectively improve IYCF practices and impact height-related growth is lacking for these specific populations. The objective of this research was to assess the effectiveness of an innovative home-based participatory play intervention on caregiver's knowledge, IYCF practices and nutritional status of low-income infants and young children in Bolivia.

\section{METHODS}

\section{Participants}

This study was conducted in the 8th district of the city of El Alto, located $4100 \mathrm{~m}$ above sea level in the Bolivian highlands. Households with pregnant women and children under 12 months old were identified using a census methodology that identified all eligible households in the catchment area. Following baseline data collection, eligible households were randomly assigned to treatment and control groups (probability of 0.5 ). The intention-to-treat households were invited to participate in the programme, and consenting households (88\%) were enrolled. An additional 14 households were recruited after the baseline survey and were randomised following the same procedure.

\section{Procedures}

This study builds on the first phase of the Community Child Nutrition (CCN) project implemented by the Andean Rural Health Board (CSRA) between 2008 and 2011. Based on evidence from the first phase, CSRA started a renewed intervention based on formative research that identified existing beliefs, preferences and practices that represented potential barriers to adequate child nutrition. ${ }^{22} 23$ The redesigned intervention introduced changes in the structure of the home visits, eliminated growth monitoring activities from home visit protocols and developed a new approach for the delivery of the culturally adapted messages.

We evaluated the effectiveness of the second phase of the CCN. The project's objectives were to improve IYCF practices, hygiene and nutritional status through an innovative behavioural change strategy based on participatory play. The strategy was delivered to individual households by trained community health workers, most of whom had formal training as nurses and doctors. Health workers were recruited through an open call where the requirements were their work experience with a focus on family and community health (at least 3 years), work experience with education entertainment, local residence (El Alto) and understanding of the native language (Aymara). Health workers were trained by the programme on nutrition (Ministry of Health standards) and management and application of programme scripts and play techniques (puppets, clown, communication skills, construction and acting of characters). Recruitment and training of personnel lasted approximately 3 months. The programme did not distribute supplements, complementary foods or provide health services.

The behavioural change strategy was directed to caregivers and family members of children younger than 12 months at baseline with the objective of delivering nutrition messages. Visits were organised along age-specific curricula called 'educational paths', which underscored key messages that caregivers should receive, depending on the child's age at each stage of the intervention from pregnancy to 24 months of age. During every visit, the educational paths emphasised one message from each of the following three areas: exclusive breastfeeding or complementary feeding, responsive feeding behaviour and hygiene (with an emphasis on handwashing). Home visits lasted 60-90 min and occurred once or twice per month, depending on the child's age (see online supplementary table A1). The messages were delivered using interpersonal communication and participatory demonstrations, enriched by an innovative approach of play education, in which programme staff conveyed the nutrition information using interactive play and performing 
arts such as puppet shows, theatre, songs or poems. The face-to-face dialogue between staff and family engaged caregivers at a cognitive and emotional level. All activities were embedded in a defined plot for each visit that reinforced key messages. Children graduated from the programme on their second birthday, regardless of the age at start.

The evaluation survey was reviewed and approved by the ethical review board of the National Bioethics Committee in Bolivia. Informed consent was obtained from the infants' parents or guardians prior to data collection, and the rights to access study data were restricted to maintain confidentiality.

\section{Outcomes}

We hypothesised that the behavioural change intervention would result in positive changes in recommended feeding and hygiene knowledge, and that the adoption of these practices would increase expenditure of recommended foods at a household level and improve the child's dietary diversity. These changes would result in improved children's nutritional status. We treated caregiver's self-reported knowledge and behaviour as intermediate outcomes. Final outcomes were anaemia and anthropometric indicators (height-for-age, stunting, weight-for-age, weight-for-height, overweight, obesity, body mass index (BMI) and head circumference z scores). Caregiver's adoption of recommended nutrition and hygiene practices was assessed using an aggregate index of responses to 43 knowledge and 20 practice questions (see online supplementary tables A2-A3). ${ }^{24}$ Each index averages the components of equally weighted questions as:

$I N D E X_{i}=\frac{\sum_{j=1}^{J} x_{i j}}{J}$, where INDEX $X_{i}$ is the index score for household $i$ and $X_{i j}$ is the binary response for household $i$ on question $j$, with $X_{i}=1$ if the caregiver responded according to recommended practice and 0 otherwise. $J$ is the total number of items in the index. We constructed separate indices for knowledge and behaviour-related questions. We converted indices to $\mathrm{z}$ scores as follows: $\mathrm{z}-I N D E X_{i}=\frac{\left(I N D E X_{i}-I N D E X_{C}\right)}{S D_{C}}$, where $\mathrm{z}-I N D E X_{i}$ is the $\mathrm{z}$ score for INDEX in household $i, I N D E X_{C}$ is the mean of INDEX in the control group and $S D_{C}$ is the $S D$ of INDEX in the control group. As a measure of current nutrition practice, we additionally drew on a household consumption module and a 24-hour recall of the child's dietary intake.

\section{Sampling, random assignment and power}

The original sample design included 2000 households with a child younger than 12 months of age or pregnant woman at baseline residing in the 8th District of El Alto. Online supplementary figure A1 presents the age distribution at recruitment. Survey teams canvassed the area for eligible households. When an eligible household was detected and provided informed consent, the household was interviewed by the survey team. Random assignment to treatment and comparison groups with equal probability was conducted by the researchers following the baseline survey. This procedure was followed by a household visit from the project several weeks later to formally enrol participants (119 households rejected at this stage). Ex ante, the study was powered (power 0.80 and significance level 0.05 ) to detect a 5 percentage-point change in stunting or $0.13 \mathrm{SD}$ change in height-for-age z score. ${ }^{22}$ Ex post estimates on the endline sample, accounting for attrition, yield a minimum detectable effect size of 0.14 SDs in height-for-age $\mathrm{z}$ scores for the intent to treat sample.

\section{Data collection}

Interviews were conducted with the mother or primary caregiver of every eligible child. Questionnaires gathered information on household sociodemographic and caregiver characteristics. At the child level, we administered questions on feeding practices and intake of individual food groups in the last 24 hours, using WHO guidelines. ${ }^{25}$ We measured children's anthropometrics and haemoglobin concentration in blood using standardised methods. Weight was measured using a SECA scale with a precision of $\pm 50 \mathrm{~g}$, height using a wood infantometer and haemoglobin was determined from capillary blood samples using a portable photometer (HemoCue model $\mathrm{HB} 201^{+}$). In addition to the endline and baseline survey data, we collected administrative data on programme implementation, enrolment, participation and graduation.

\section{Statistical analysis}

Treatment effects were estimated using multivariate regression analysis, comparing outcomes in the treatment and control groups with and without controlling for covariates. Statistical analysis was conducted in STATA (V.14.0). We ran the following reduced form model to estimate intent-to-treat effects:

$$
Y_{i}=\alpha+\beta T_{i}+\sum_{j=1}^{n} \boldsymbol{X}_{i j}+\epsilon_{i} .
$$

Where $Y_{i}$ is the outcome of interest for household or individual $i$ and $T_{i}$ is a binary variable equal to 1 in the treatment group and 0 otherwise. $\beta$ is the average intentto-treat effect. $X_{i j}$ is $j$ household, caregiver or child covariates included to reduce residual variance in adjusted models. The key outcomes examined at endline consisted of a battery of caregiver knowledge and feeding practice indices, household food expenditure, child dietary diversity, the set of aforementioned anthropometric indicators and haemoglobin levels. We used the WHO Anthro software V.3.2.2 (January 2011) for the construction of standardised anthropometric z score measures. ${ }^{26}$ Child gender and age were included as covariates to increase precision. Additional regressions were performed to account for potential heterogeneous treatment effects (online supplementary tables A4-A8). We ran the same model interacting treatment with gender, for children 
with a height-for-age $\mathrm{z}$ score lower than -1 and lower than -2 at baseline, for the subsample of children whose mothers completed less than 5 years of education, as well as Kolmogorov-Smirnoff tests on the distribution of anthropometric outcomes by age and gender at endline.

\section{Role of the funding source}

Baseline data collection and part of the programme's implementation costs were funded by the Inter-American Development Bank (IDB) grant BO-T1181 (ATN/ JO-13606-BO), 'Improving Child Nutrition Services in Bolivia', a technical cooperation project financed through a donation from the IDB's Japan Special Fund Poverty Reduction Programme (JPO) and executed by the CSRA, in coordination with the Ministry of Health and local public health centres in El Alto. Endline data collection was conducted by the Center for Generation of Information and Statistics at the Bolivian Private University and funded through the IDB grant BO-T1259 (ATN/ OC-15554-BO), 'Effectiveness of Community Interventions to Reduce Child Malnutrition', executed by the IDB. All opinions in this paper are those of the authors and do not necessarily represent the views of the JPO, CSRA, Ministry of Health or of the IDB, its Executive Directors or the governments they represent.

The authors declare no financial or other competing interests in the results of the study.

\section{RESULTS}

\section{Balance and attrition}

The baseline survey was conducted between March and July of 2014. Table 1, panel 1 presents descriptive statistics for selected household, caregiver and child characteristics at baseline. Baseline characteristics were balanced based on treatment and control assignments. ${ }^{22}$

The endline survey was conducted between September 2016 and January 2017, approximately 30 months after baseline, tracking all children and caregivers interviewed at baseline. Sample attrition between baseline and endline was $21 \%$ overall and was balanced between treatment and control groups (table 2). Attrition was also balanced in the subcategories of reject survey (7\%), no contact $(8 \%)$, child deceased $(2.3 \%)$ and household migrated outside of La Paz or El Alto (5\%). There is no evidence of selective attrition based on treatment assignment (online supplementary table A9).

At baseline, $17 \%$ of children were stunted (heightfor-age $\mathrm{z}$ score $<-2 \mathrm{SD}), 2.4 \%$ suffered from wasting (weight-for-height z score $<-2 \mathrm{SD}$ ) and $7.8 \%$ (unbalanced) were overweight or obese (body mass index z score $>2$ ). Among caregivers, $81 \%$ identified as indigenous, and $91 \%$ were married or lived in a domestic partnership. Caregivers completed, on average, 9 years of education, and $31 \%$ worked regularly. The housing and hygienic conditions in the study area were precarious: $36 \%$ had access to public sewerage, and $83 \%$ of households used toilets or pit latrines located outside the house, mostly without a functioning sink for handwashing.

\section{Treatment compliance}

We analysed treatment compliance using administrative records and self-reports. Two control households (out of 1007) were unintentionally enrolled in the treatment group. At endline, $66 \%$ of households completed the programme in the treatment group (enrolled child graduated at age 24 months). Of the $34 \%$ who did not complete the programme, $22 \%$ were enrolled but did not complete it, and $12 \%$ did not enrol after baseline. In total, $73 \%$ of households in the treatment group self-reported participating in the programme, whereas $6 \%$ of control households reported participating (table 1, panel 3 ). Even though randomisation occurred at the household level within the same district, only $9.7 \%$ of control households reported having heard about the programme. Figure 1 summarises the trial profile.

\section{Caregiver knowledge and practices}

Table 3, panel A, presents programme impacts on the knowledge, practices and nutritional indicators collected at endline and described in the Methods section. The unadjusted treatment effect on caregiver nutrition knowledge (43 items) represents an increase of 0.17 SDs. The overall effects on feeding practices (20 items) showed a significant effect of 0.20 SDs $(p<0.01)$. Consistent with the positive results on caregiver's knowledge and practices, we also found positive impacts on households' food expenditure on meats and fruit (significant at the 5\% level) and dairy and eggs (significant at the 10\% level), which were food items promoted by the programme (table 3, panel B). Expenditures on breads and cereals, oils, tubers and legumes and fresh vegetables presented a positive but non-significant difference. Expenditures on sugars, salt and condiments, drinks and food outside the home showed a non-statistically significant negative tendency, also consistent with the programme's messages that discouraged intake of these foods. The increase in food expenditure translated into increased dietary diversity for the child, a measure of consumption of seven key food groups (table 3 , panel C).$^{25}$ The proportion of children who score above the conventional threshold of four or more food groups is $94 \%$ in both treatment and control groups. However, children in the treatment group score $4.1 \%$ and $5.4 \%$ points higher on the consumption of five and six or more food groups, respectively. For hygiene behaviour, while handwashing was not measured, direct observation by the surveyor of children with dirty hands and face and dirty clothes reveals no difference between treatment and control groups (table 3, panel D).

\section{Anthropometric measurements and anaemia}

Table 3, panel E presents the observed endline results on anthropometric indicators. Despite significant effects on feeding practices and caregiver's knowledge, we found no significant effects on anthropometric indicators 


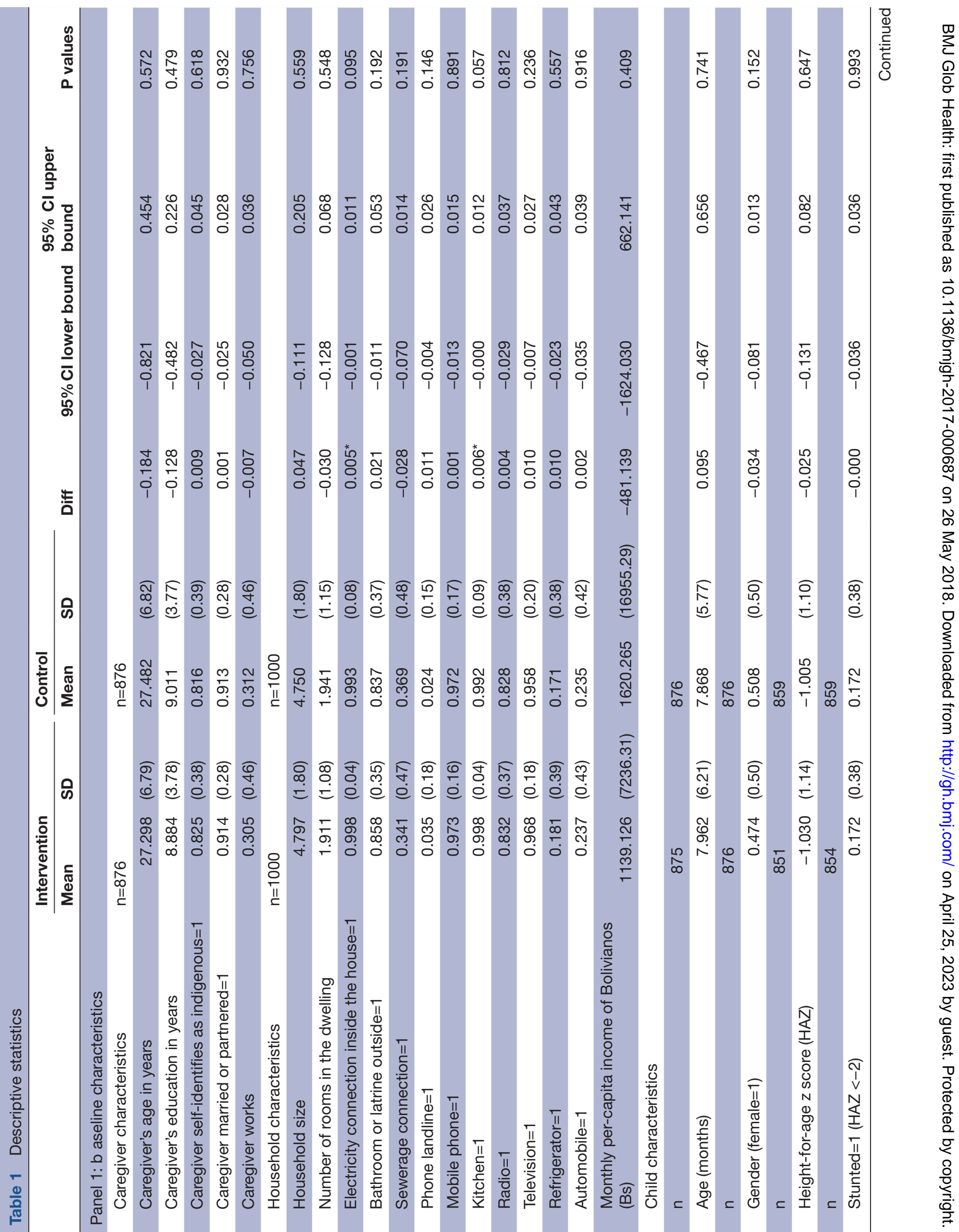




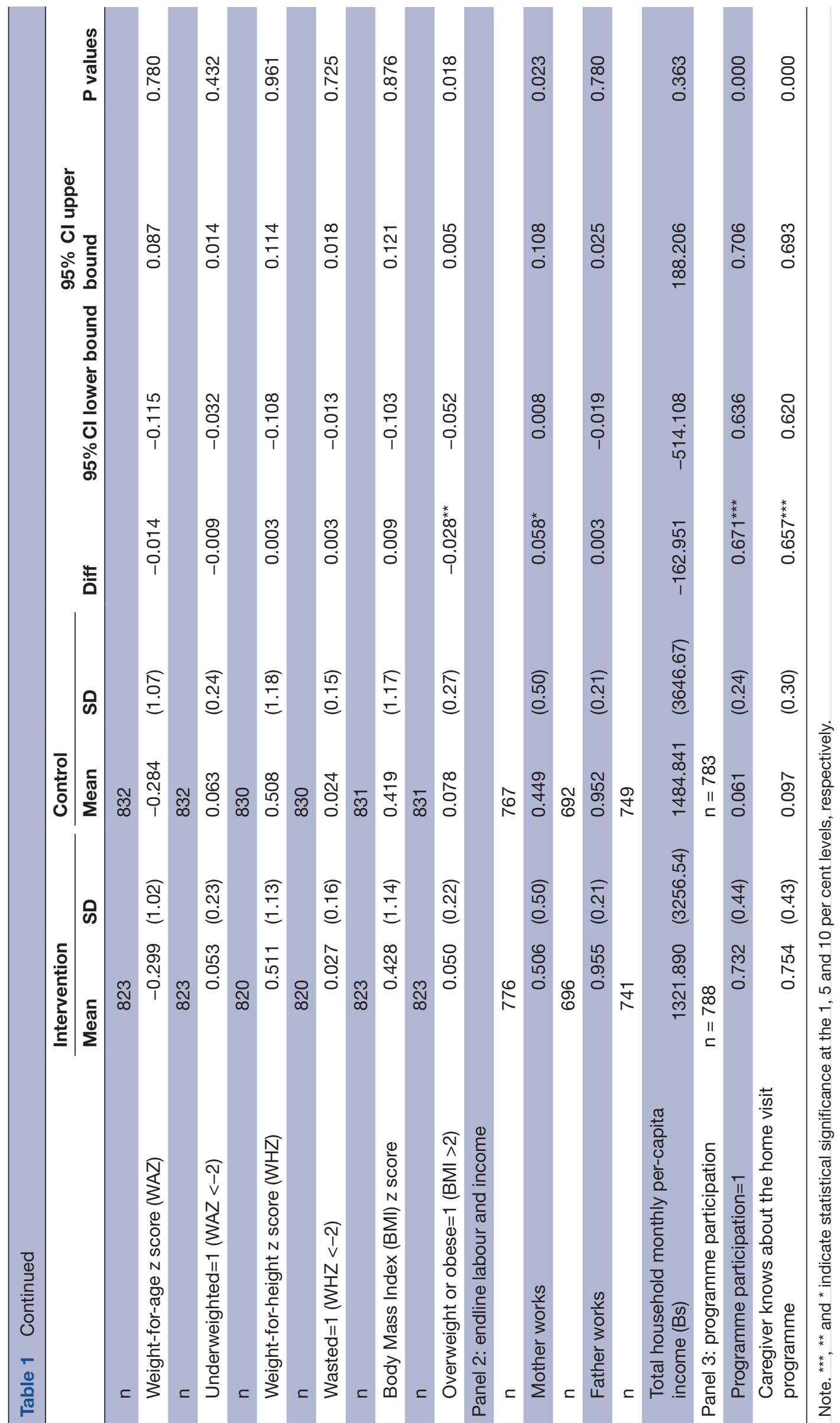

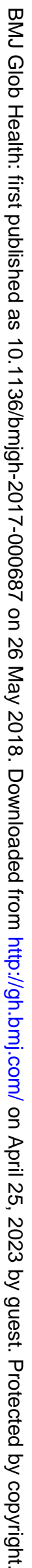


Table 2 Sample attrition

\begin{tabular}{|c|c|c|c|c|c|c|c|c|}
\hline \multirow[b]{2}{*}{ Category } & \multicolumn{2}{|c|}{ Treatment $(n=1003)$} & \multicolumn{2}{|c|}{ Control (n=1005) } & \multirow[b]{2}{*}{ Diff } & \multirow[b]{2}{*}{ Lower bound } & \multirow[b]{2}{*}{ Upper bound } & \multirow[b]{2}{*}{$P$ values } \\
\hline & Mean & SD & Mean & SD & & & & \\
\hline Rejected survey & 0.056 & $(0.23)$ & 0.069 & $(0.25)$ & -0.013 & -0.034 & 0.008 & 0.235 \\
\hline No contact & 0.082 & $(0.27)$ & 0.080 & $(0.27)$ & 0.002 & -0.022 & 0.026 & 0.870 \\
\hline Child died & 0.021 & $(0.14)$ & 0.023 & $(0.15)$ & -0.002 & -0.015 & 0.011 & 0.761 \\
\hline Household migrated & 0.051 & $(0.22)$ & 0.046 & $(0.21)$ & 0.005 & -0.014 & 0.024 & 0.603 \\
\hline Total & 0.209 & 0.407 & 0.217 & 0.412 & -0.008 & -0.043 & 0.028 & 0.680 \\
\hline
\end{tabular}

(weight-for-age, height-for-age, BMI-for-age, weight-forlength z scores, head circumference, stunting and wasting) or anaemia. Secondary analysis in online supplementary figures A2-A5 plots the average and 95\% CI for heightfor-age and BMI-for-age $\mathrm{z}$ scores by age (months) and income (decile) for treatment and control groups, with

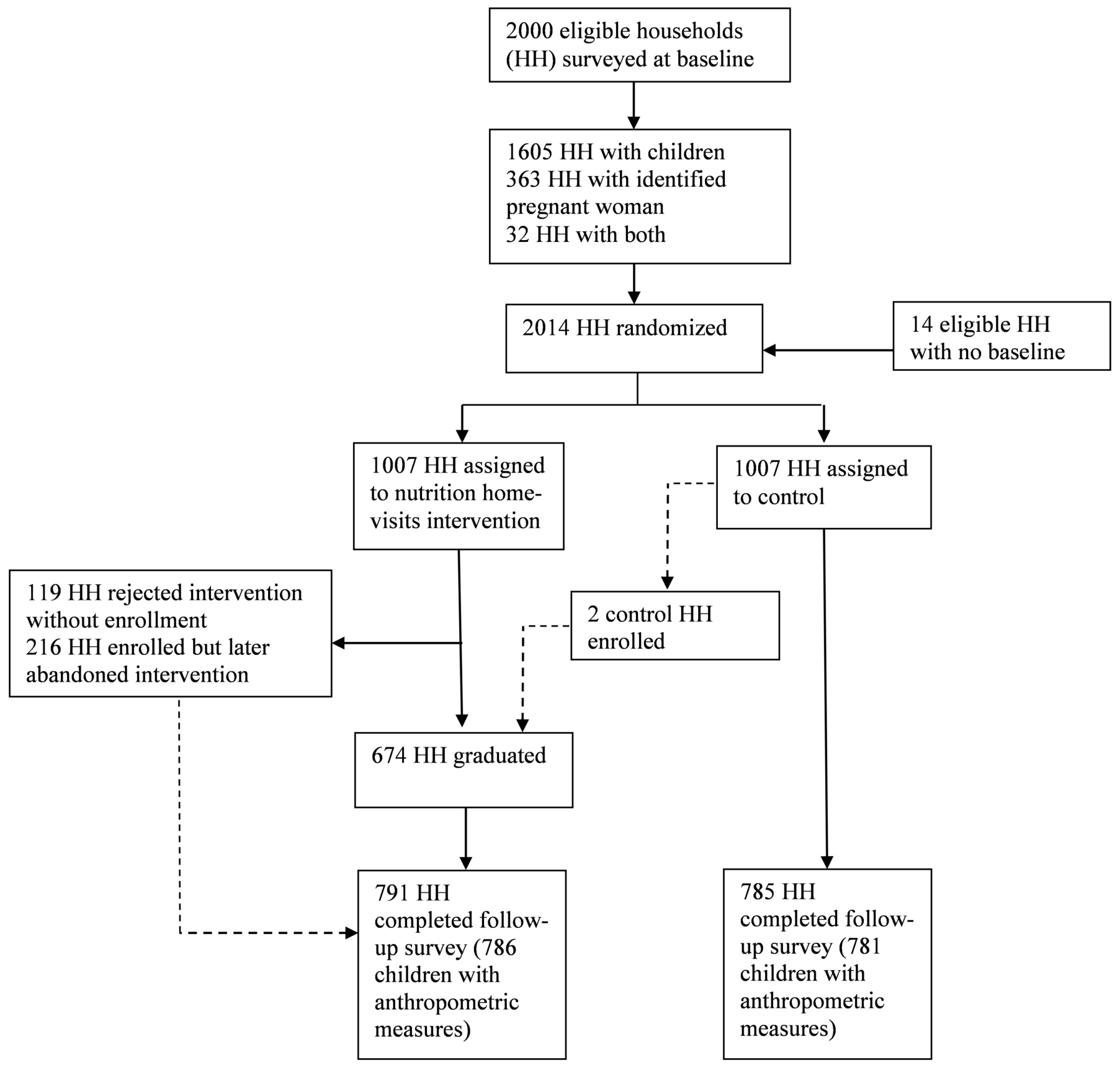

Figure 1 Trial profile. 


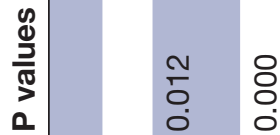

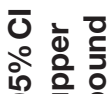

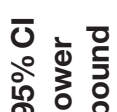

ᄃ

㛃品

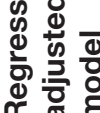

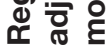

$\frac{\text { @ }}{\frac{1}{3}}$

$\begin{array}{ll}5 & 8 \\ 0 & 8 \\ 0 & 0\end{array}$

$\begin{array}{ll}0 & 0 \\ 0 & 0 \\ 0 & 0 \\ 0 & 0\end{array}$

$\stackrel{ }{\circ}$

o

㞼

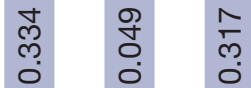

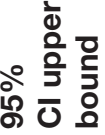

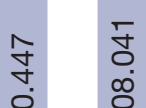

ㅇำ

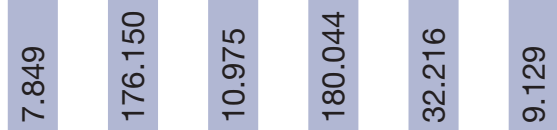

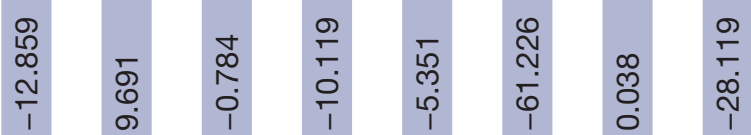

ర̄

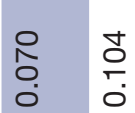

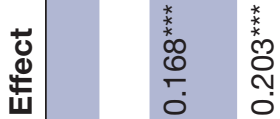

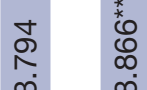

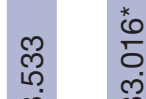

要

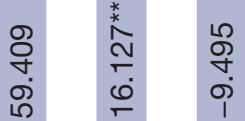

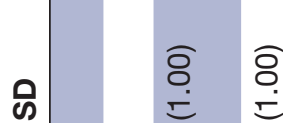

$\varpi$
$\infty$
$\infty$
$\infty$
$\infty$

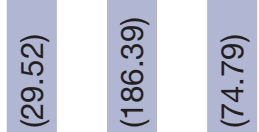

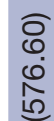

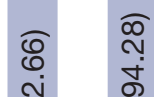

$\stackrel{8}{=}$

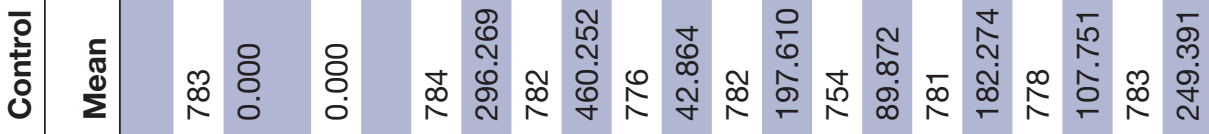

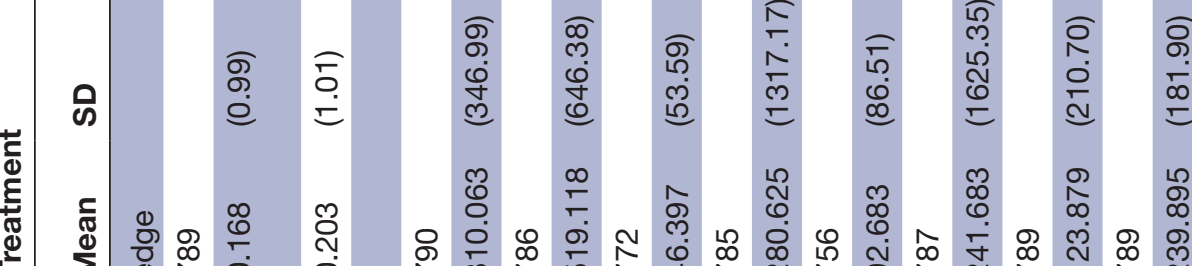

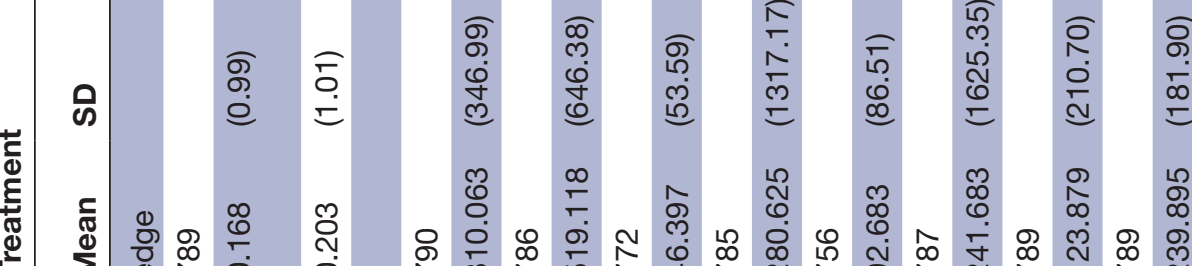

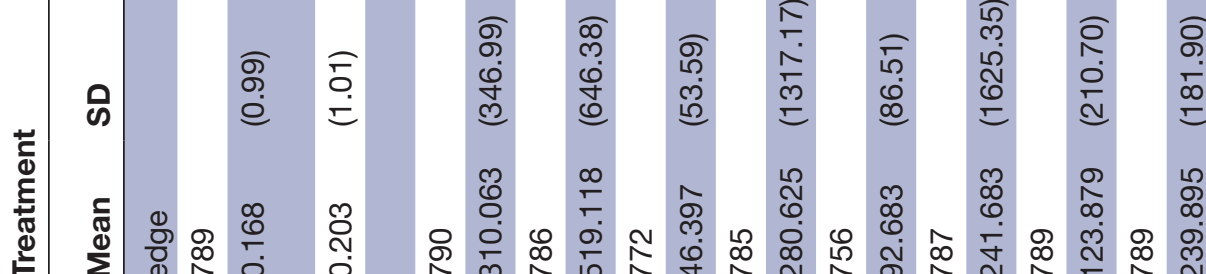

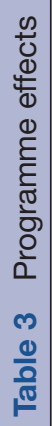

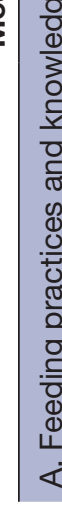

$\frac{x}{0}$

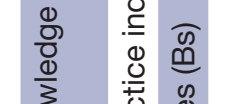

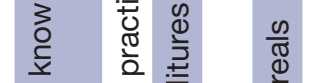

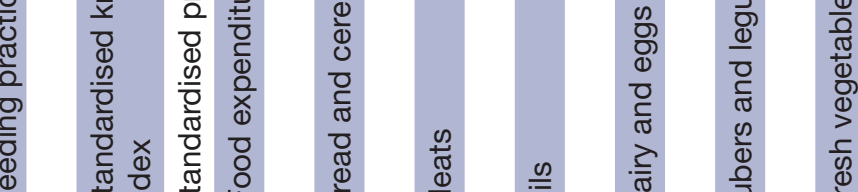

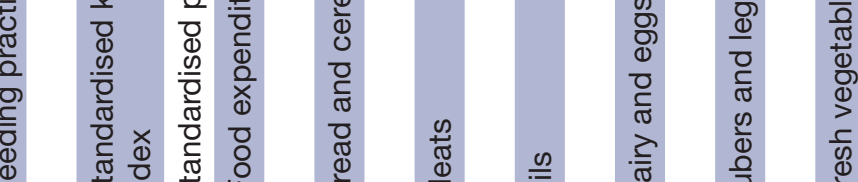

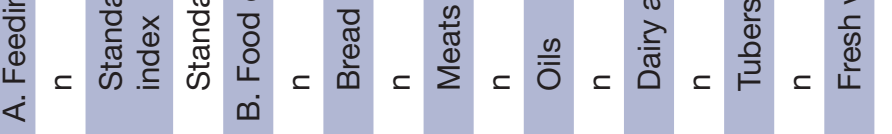

\begin{abstract}
政
\end{abstract}

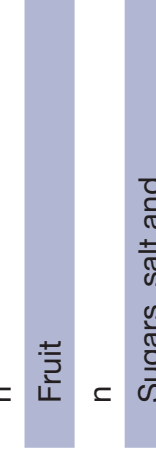$$
\text { 政 }
$$

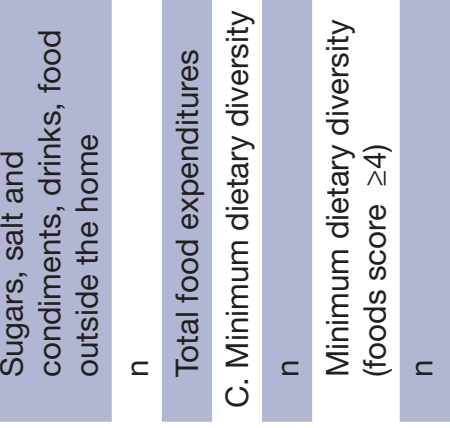




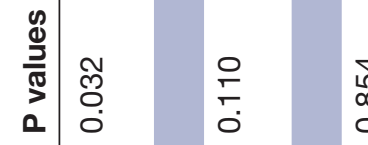

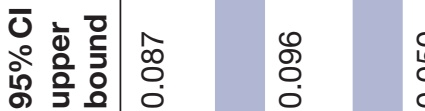

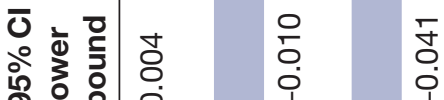

흐

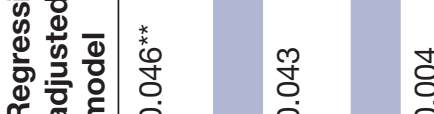

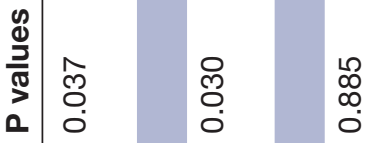

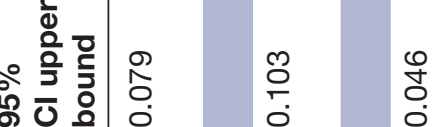

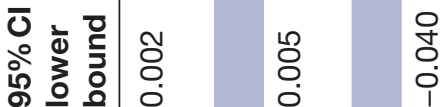

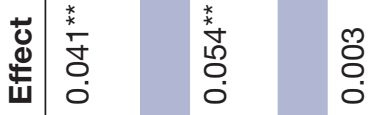

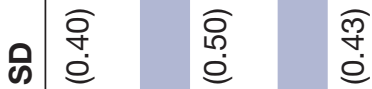

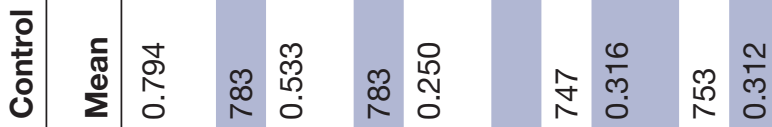

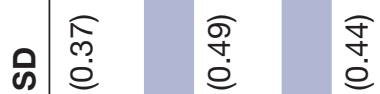

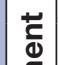

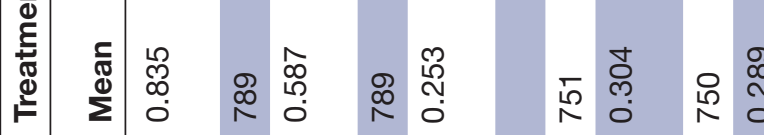

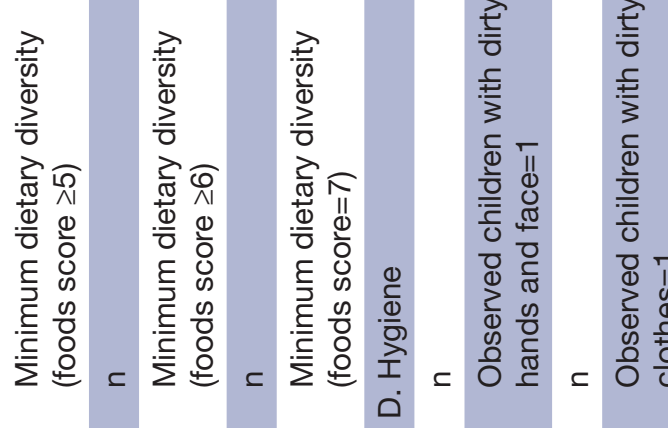

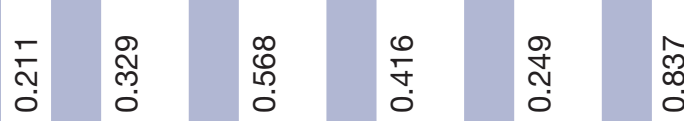

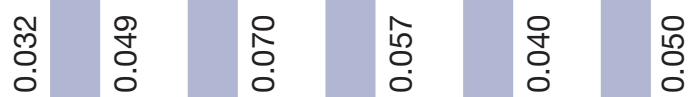

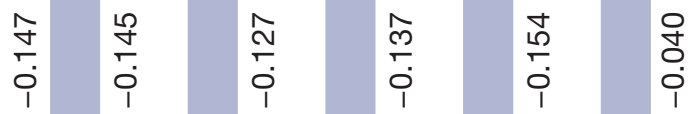

$\begin{array}{llllll}\hat{0} & 0 & 0 & 0 & 0 & 0 \\ 0 & 0 & 0 & 0 \\ 0 & 0 & 0 & 0 \\ 0 & 1 & 0 & 0 & 0\end{array}$

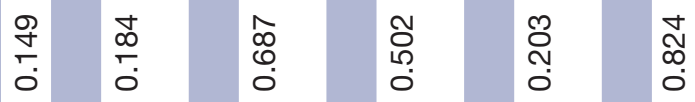

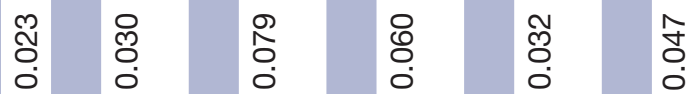

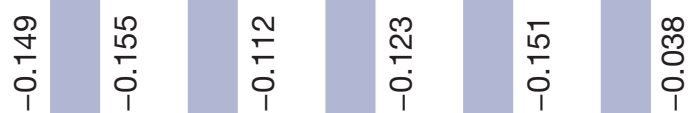

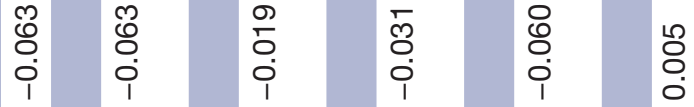

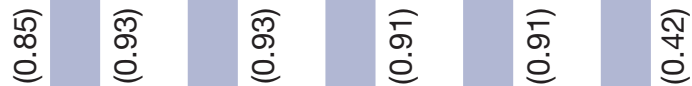

京管

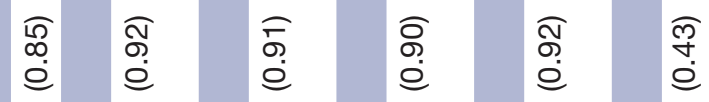

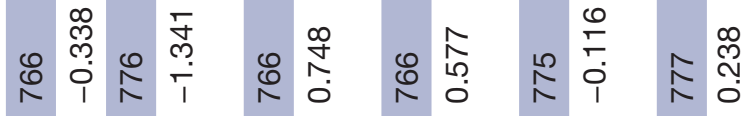

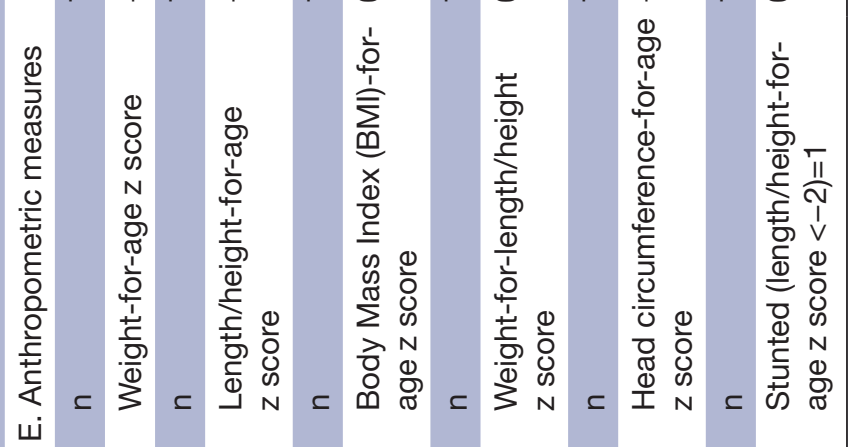

$\frac{\substack{0 \\ \frac{0}{2}}}{\frac{0}{2}}$

$\frac{\sqrt[3]{0}}{\sqrt[0]{1}}$

?ִ.

蛋

음

$\frac{\operatorname{mon}}{\bar{\Phi}}$

क

$\vec{\circ}$

$\vec{\sigma}$

$\frac{\sqrt{3}}{3}$

ํํำ

ठ̀

음

N

3

옹

망

ํㅡㅇ

$\frac{0}{8}$

웅

룽

윽

욱

ญิ

웅

음

N

N

ర

음 


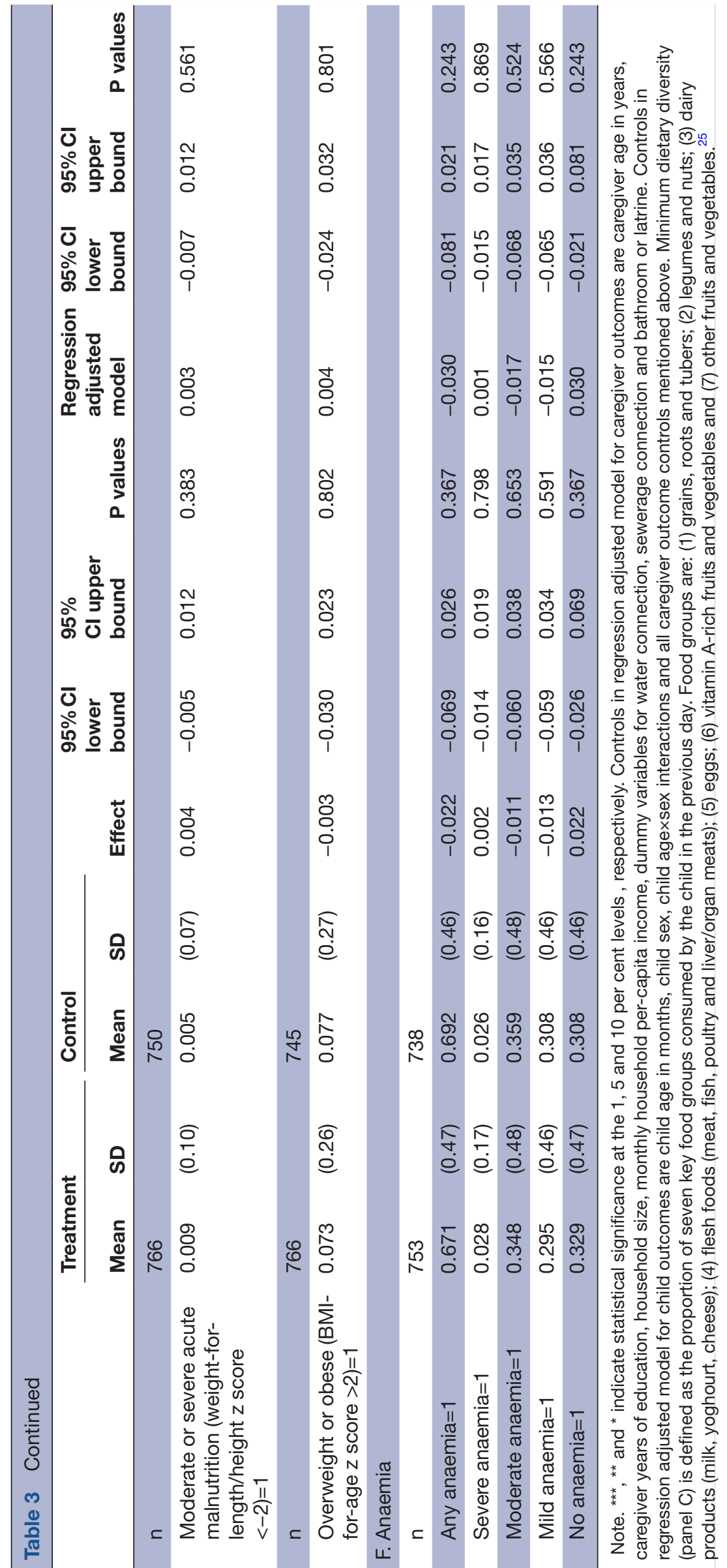


no systematic differences in these outcomes by age or income. Online supplementary tables A4-A8 further analyse heterogeneous effects by gender and age, baseline stunting and mother's education. They also revealed no detectable impacts of the programme. Table 3, panel $\mathrm{F}$ presents results on anaemia prevalence. Approximately $69 \%$ of children were anaemic at endline primarily concentrated in the mild and moderate categories. No significant effects of the programme were detected on the prevalence of anaemia.

\section{DISCUSSION}

We conducted an effectiveness trial of an innovative behavioural change strategy based on participatory play in the city of El Alto, Bolivia. The strategy promoted recommended IYCF practices and hygiene through home visits provided by trained community health workers. The nutrition and hygiene content was delivered using interpersonal communication alongside interactive, playful education methods, which had been adapted to the local cultural context based on formative research. The intervention was implemented according to design, and enrolment compliance reached $88 \%$ at entry. Overall, $66 \%$ of the intent-to-treat sample completed the programme.

The intervention significantly improved caregivers' knowledge and feeding practices, including complementary feeding, micronutrient supplementation and iron-rich food consumption, as well as increased household expenditures on recommended food items and diet diversification of five and six or more recommended food groups. This is a relevant result in the socioeconomic and environmental context of El Alto, due to the potential relationship between improved feeding practices and the reduction of risk of mortality and motor and language development. ${ }^{1427}$ We found no effects on hygiene or final outcomes of nutritional status (height, weight or anaemia). The behavioural change strategy was specifically designed to promote adequate feeding practices, including reducing intake of sugars, fat and salt. No evidence of unintended effects of the intervention on overweight and obesity was found at endline (7\% population prevalence). Given the potential side effects of nutrition interventions focused on improving feeding practices, especially in areas prone to the 'double burden of malnutrition', we consider this result a notable outcome. $^{23}$

The observed positive effects on knowledge and practices confirm that IYCF practices can be modified through community-based behavioural change strategies. However, the magnitude of change in practices observed between treatment and control groups $(0.20$ SDs) might have not been sufficiently large to affect anthropometric indicators. The absence of impact on indicators of nutritional status in this study adds to the heterogeneity in weight and/or height effects found in the literature. Since countries have committed many resources to reduce stunting and achieve the Sustainable
Development Goals by 2030, this research highlights the relevance of contextual variables and other determinants of malnutrition, apart from diet (eg, maternal nutrition and inflammation), that could be driving linear growth in this population.

Our results add to the mixed results observed on the impact of behavioural change interventions to improve IYCF practices and linear growth. A review conducted in 2014 on the effect of education on complementary feeding and linear growth found that education had a significant impact on linear growth in food secure and food insecure populations and stunting reduction only in food insecure populations. ${ }^{17}$ The review included studies with relatively small sample sizes (maximum 190 children in the intervention group), and authors concluded that larger randomised trials are necessary to assess the impact of education interventions on growth. A more recent randomised large-scale behavioural change intervention conducted in Bangladesh found similar results as our study. Larger impacts on IYCF practices were observed in the group receiving an intensive intervention relative to the non-intensive group. Even larger impacts on IYCF practices than the ones found in El Alto did not result in a positive impact on linear growth. ${ }^{28}$ The authors' potential explanations for their results include: (1) the overall improvement of nutritional status in Bangladesh, (2) other constraints on linear growth not addressed by the intervention, (3) the inability to adhere to practices on a routine basis and (4) illness or poorer growth trajectories not measured in the study. The last three explanations could also be applicable to the results observed in our study.

Additionally, four of the potential explanations by Shi (2011) for the heterogeneity on anthropometric outcomes are germane in the context of this study. ${ }^{16}$ First, our study population has substantial variation in children's age at enrolment and follow-up. Although the intervention was designed to capture children beginning at pregnancy, enrolment was permitted up to the age of 12 months, which led to variations in the length of exposure and age range during participation. However, the average length of exposure of 15 months exceeds that of other community-based education interventions that found impacts on height after 12 months of programme duration. ${ }^{29-32}$ In terms of age range, we did not find evidence of differential effects when disaggregating the analysis by age groups, although small sample sizes and insufficient statistical power limit age-disaggregated analysis.

The second potential explanation is related to individual nutritional status at entry. Our evidence suggests that initial nutritional status was not associated with improved outcomes. Therefore, the intervention effects were not influenced by children's baseline nutrition status, as has been previously suggested. ${ }^{17}$ This result differs from previously reported effects that suggested larger improvements in participants with lower baseline nutritional status. 
The third aspect refers to the project's operational strategy and intensity. The educational activities were limited to individual home visits with intensive faceto-face communication and the use of performing arts and play education techniques. However, other forms of education, including group meetings for recipe sharing or reinforcement, community mobilisation through influential community or family members, additional in-depth counselling by peers, laypersons or professionals and complementary health services for the management of childhood diseases, were not provided. And above all, the intervention did not include any food supplementation. The aforementioned are all aspects that differ among nutrition programmes around the world and likely play a role in the achieved behavioural change and effects on dietary composition and diversity that eventually translate into growth.

Finally, the broader geographical and socioeconomic context of the intervention is relevant, especially when considering the potential dominance of contextual nutrition-sensitive factors such as sanitation, healthcare and income in the intervention area. For example, the lack of access to sewerage in the intervention area could promote infectious diseases and chronic problems of the intestinal tract (environmental enteropathy among infants), thereby affecting biological growth outcomes. ${ }^{33}$

\section{Study strengths and limitations}

We present the results of a transition-to-scale effectiveness trial that goes beyond small-scale studies in scope, sample size and duration. The study population includes children under 12 months at baseline, age at which IYCF practice interventions have more potential to be effective. The experimental design with random assignment of a large sample of households to treatment and control groups allows for credible estimates of programme effects. Limitations of this study include a high attrition rate of approximately $21 \%$ (balanced across treatment assignment), the lack of baseline IYCF practices in the whole sample and anthropometric measures on the subsample of children recruited prior to birth (approximately $20 \%$ of the sample).

\section{CONCLUSION}

Various policy lessons can be derived from this study. The delivery model we study here, including interactive play, is a promising way of providing education and counselling to elicit knowledge acquisition and behavioural change and also offers a novel delivery platform for additional interventions such as supplementation or provision of fortified complementary foods. Under similar conditions, behavioural change strategies may have more impact on a child's well-being if they are part of an integral approach to improve maternal and child nutrition, increase access to water and sanitation, reduce poverty and improve healthcare access and quality. In other words, behavioural change strategies can be considered an effective component of health policies, but alone they may not be sufficient to improve final anthropometric outcomes. Further research is needed to investigate whether the explicit involvement of influential community leaders or family members might increase the impact and sustainability of nutrition-related behavioural change in the intervention area. Further research should also examine whether the innovative home-based participatory play delivery model, combined with other interventions such as nutritional supplementation and integrated maternal and child healthcare, could effectively improve nutrition outcomes. Furthermore, additional research is needed to compare the cost-effectiveness of the participatory play method to that of alternative education methods for delivering nutrition messages. Finally, longer term follow-ups are necessary to measure whether the observed changes in nutrition practice are sustained over time and translate into growth and other functional outcomes of child's well-being such as health and cognitive development that would promote human capital and economic development.

Acknowledgements The authors are grateful to the families and community health workers in El Alto who participated in this study. The authors thank Anastasiya Yarygina for outstanding research assistance.

Contributors SM, JJ, GG, ABPE, RMB, IC, RL and AMA: conceived and designed the study and discussed, critically revised and approved the study protocol. All authors: wrote the paper, drafted the first version of the report and elaborated, discussed and approved the final version of the report and the paper for publication. SM, JJ, GG, RMB, IC, JFA, RL, NA, CL, CF, TR and AMA: responsible for the organisation and conduct of the study. SM, JJ, GG, NA, CL, TR and AMA: supervised the study. TR, MC, CF and SA: collected the data. SM and JF: responsible for the statistical analysis. JJ, GG, ABPE, RMB and AMA: contributed to the data analysis.

Funding Baseline data collection and part of the programme's implementation costs were funded by the Inter-American Development Bank (IDB) grant B0-T1181 (ATN/JO-13606-BO), 'Improving Child Nutrition Services in Bolivia', a technical cooperation project financed through a donation from the IDB's Japan Special Fund Poverty Reduction Program (JPO) and executed by the CSRA, in coordination with the Ministry of Health and local public health centres in El Alto. Endline data collection was conducted by the Center for Generation of Information and Statistics (CEGIE) at the Bolivian Private University and funded through the IDB grant B0-T1259 (ATN/OC-15554-B0), 'Effectiveness Of Community Interventions to Reduce Child Malnutrition', executed by the IDB.

Patient consent Parental/guardian consent obtained.

Ethics approval The evaluation survey was reviewed and approved by the ethical review board of the National Bioethics Committee in Bolivia.

Provenance and peer review Not commissioned; externally peer reviewed.

Data sharing statement All non-identifiable data will be made available through the Inter-American Development Bank's publications website.

Open Access This is an Open Access article distributed in accordance with the Creative Commons Attribution Non Commercial (CC BY-NC 4.0) license, which permits others to distribute, remix, adapt, build upon this work non-commercially, and license their derivative works on different terms, provided the original work is properly cited and the use is non-commercial. See: http://creativecommons.org/ licenses/by-nc/4.0/

(c) Article author(s) (or their employer(s) unless otherwise stated in the text of the article) 2018. All rights reserved. No commercial use is permitted unless otherwise expressly granted.

\section{REFERENCES}

1. Black RE, Allen LH, Bhutta ZA, et al. Maternal and child undernutrition: global and regional exposures and health consequences. Lancet 2008;371:243-60. 
2. Ozaltin E, Hill K, Subramanian SV. Association of maternal stature with offspring mortality, underweight, and stunting in low- to middleincome countries. JAMA 2010;303:1507-16.

3. Dewey KG, Begum K. Long-term consequences of stunting in early life. Matern Child Nutr 2011;7(Suppl. 3):5-18.

4. Grantham-McGregor S, Cheung YB, Cueto S, et al. Developmental potential in the first 5 years for children in developing countries. Lancet 2007;369:60-70.

5. Victora CG, Adair L, Fall C, et al. Maternal and child undernutrition: consequences for adult health and human capital. Lancet 2008;371:340-57.

6. Hoddinott J, Maluccio JA, Behrman JR, et al. Effect of a nutrition intervention during early childhood on economic productivity in Guatemalan adults. Lancet 2008;371:411-6.

7. de Onis M, Branca F. Childhood stunting: a global perspective. Matern Child Nutr 2016;12 (Suppl 1):12-26.

8. UNICEF, WHO, World Bank Group. Joint Child Malnutrition Estimates. Key findings of the 2017.

9. World Health Organization/UNICEF. Global strategy for infant and young child feeding. Geneva: World Health Organization, 2003.

10. Bhutta ZA, Ahmed T, Black RE, et al. What works? Interventions for maternal and child undernutrition and survival. Lancet 2008;371:417-40.

11. Michaelsen KF, Grummer-Strawn L, Bégin F. Emerging issues in complementary feeding: Global aspects. Matern Child Nutr 2017:13 (Suppl 2):e12444.

12. Osendarp SJ, Roche ML. Behavioral Change Strategies for Improving Complementary Feeding and Breastfeeding. World Rev Nutr Diet 2016:115:184-92.

13. Sanghvi T, Seidel R, Baker J, et al. Using behavior change approaches to improve complementary feeding practices. Matern Child Nutr 2017;13 (Suppl 2):e12406.

14. Dewey KG, Adu-Afarwuah S. Systematic review of the efficacy and effectiveness of complementary feeding interventions in developing countries. Matern Child Nutr 2008;4 (Suppl 1):24-85.

15. Imdad A, Yakoob MY, Bhutta ZA. Effect of breastfeeding promotion interventions on breastfeeding rates, with special focus on developing countries. BMC Public Health 2011;11 (Suppl 3):S24.

16. Shi L, Zhang J. Recent evidence of the effectiveness of educational interventions for improving complementary feeding practices in developing countries. J Trop Pediatr 2011;57:91-8.

17. Lassi ZS, Das JK, Zahid G, et al. Impact of education and provision of complementary feeding on growth and morbidity in children less than 2 years of age in developing countries: a systematic review. BMC Public Health 2013;13 (Suppl 3):S13.

18. Sunguya BF, Poudel KC, Mlunde LB, et al. Effectiveness of nutrition training of health workers toward improving caregivers' feeding practices for children aged six months to two years: a systematic review. Nutr J 2013;12:66.

19. Fabrizio CS, van Liere M, Pelto G. Identifying determinants of effective complementary feeding behaviour change interventions in developing countries. Matern Child Nutr 2014;10:575-92.
20. Krasevec J, An X, Kumapley R, et al. Diet quality and risk of stunting among infants and young children in low- and middle-income countries. Matern Child Nutr 2017;13 Suppl 2(S2):e12430.

21. Penny ME, Creed-Kanashiro HM, Robert RC, et al. Effectiveness of an educational intervention delivered through the health services to improve nutrition in young children: a cluster-randomised controlled trial. Lancet 2005;365:1863-72.

22. Gertner G, Johannsen J, Martinez S, et al. nutrición y saneamiento entre los niños menores de 12 meses en el Distrito 8 de El Alto: Resultados de encuesta de línea de base del Programa de Mejoramiento Nutricional en El Alto, Bolivia fase II. IDB technical Note No. IDB-TN-1118. Inter-American Development Bank 2016.

23. Gertner G, Johannsen J, Martinez S. Effects of Nutrition Promotion on Child Growth in El Alto, Bolivia: Results from a Geographic Discontinuity Design. Economia Journal of the Latin American and Caribbean Economic Association 2016;17:131-65.

24. Kling JR, Liebman JB, Katz LF. Experimental Analysis of Neighborhood Effects. Econometrica 2007;75:83-119.

25. World Health Organization, UNICEF, USAID, AED, UCDAVIS, IFPRI. Indicators for assessing infant and young child feeding practices. Geneva: World Health Organization, 2010.

26. World Health Organization. WHO Anthro (version 3.2.2, January 2011) and macros. http://www.who.int/childgrowth/software/en/ (accessed 14 Oct 2016).

27. Frongillo EA, Nguyen PH, Saha KK, et al. Large-scale behaviorchange initiative for infant and young child feeding advanced language and motor development in a cluster-randomized program evaluation in Bangladesh. J Nutr 2017;147:256-63.

28. Menon P, Nguyen PH, Saha KK, et al. Combining intensive counseling by frontline workers with a nationwide mass media campaign has large differential impacts on complementary feeding practices but not on child growth: Results of a cluster-randomized program evaluation in Bangladesh. J Nutr 2016;146:2075-84.

29. Bhandari N, Mazumder S, Bahl R, et al. An educational intervention to promote appropriate complementary feeding practices and physical growth in infants and young children in rural Haryana, India. $J$ Nutr 2004:134:2342-8.

30. Salehi M, Kimiagar SM, Shahbazi M, et al. Assessing the impact of nutrition education on growth indices of Iranian nomadic children: an application of a modified beliefs, attitudes, subjective-norms and enabling-factors model. Br J Nutr 2004;91:779-87.

31. Guldan GS, Fan HC, Ma X, et al. Culturally appropriate nutrition education improves infant feeding and growth in rural Sichuan, China. J Nutr 2000;130:1204-11.

32. Vazir S, Engle P, Balakrishna N, et al. Cluster-randomized trial on complementary and responsive feeding education to caregivers found improved dietary intake, growth and development among rural Indian toddlers. Matern Child Nutr 2013:9:99-117.

33. Bancalari A, Martinez S. Exposure to sewage from on-site sanitation and child health: a spatial analysis of linkages and externalities in peri-urban Bolivia. Journal of Water Sanitation and Hygiene for Development 2018;8:90-9. 